\title{
Development of a Rapid RT-PCR Test for the Detection of Peach Latent Mosaic Viroid, Pear Blister Canker Viroid, Hop Stunt Viroid and Apple Scar Skin Viroid in Fruit Trees from Tunisia
}

\author{
I. Fekih Hassen ${ }^{1,2}$, S. Roussel ${ }^{1}$, J. Kummert ${ }^{1}$, H. FAKhfakh ${ }^{2}$, M. MARrakchi ${ }^{2}$ and M. H. JiJakli ${ }^{1}$ \\ Authors' addresses: ${ }^{1}$ Plant Pathology Unit, Faculté Universitaire des Sciences Agronomiques, Passage des Déportés 2, 5030 \\ Gembloux, Belgium; ${ }^{2}$ Laboratory of Molecular Genetic, Immunology and Biotechnology, Faculty of Sciences of Tunis, 2092 \\ Elmanar Tunis, Tunisia (correspondence to M. H. Jijakli. E-mail: jijakli.h@fsagx.ac.be)
}

Received July 13, 2005; accepted December 2, 2005

Keywords: detection, fruit trees, RT-PCR, Tunisia, viroids

\begin{abstract}
A reverse transcription polymerase chain reaction was developed to investigate the occurrence of 'peach latent mosaic viroid' (PLMVd), 'pear blister canker viroid' (PBCVd), 'hop stunt viroid' (HSVd) and 'apple scar skin viroid' (ASSVd) on fruit trees (peach, pear, almond and apple) in Tunisia. The test was initially performed with total RNA preparations from selected isolates and then applied to total RNA preparations from leaf or bark tissues of fruit trees collected in the north of Tunisia and the Sahel. PLMVd was found to occur in peach and pear trees, HSVd in pear, peach and almond trees, and PBCVd in pear trees. Mixed PBCVd-HSVd and PLMVd-HSVd infections occurred naturally in pear trees. ASSVd was not detected in any samples from apple trees. The identity of the detected viroids was confirmed by comparing their sequences with those of other previously characterized isolates. The test was then simplified by direct use of diluted crude plant extracts. The results obtained from crude sap extracts of leaves or bark tissues and from total RNA preparations were identical. This improved test is thus quick and useful for large-scale routine analysis. It can be used in a certification programme to contribute to prevention of the occurrence and spread of PLMVd, HSVd, PBCVd and ASSVd in Tunisia.
\end{abstract}

\section{Introduction}

Tunisia is a major producer of fruits such as apples, pears, almonds and peaches. Pome and stone fruit trees can be infected by viroids, characterized by single-stranded circular RNA molecules ranging between 246 and 399 nucleotides (Diener, 1971; Flores et al., 1998). 'Peach latent mosaic viroid' (PLMVd), 'pear blister canker viroid' (PBCVd), 'apple scar skin viroid'
(ASSVd) and 'hop stunt viroid' (HSVd), which infect temperate fruit trees, have a major impact on fruit production (Randles, 2003). These viroids occur in various countries of Europe, America and Asia (Flores et al., 1990; Yang et al., 1992; Hadidi et al., 1997; Osaki et al., 1999; Kyriakopoulou et al., 2001).

Peach trees are hosts of HSVd (Sano et al., 1989; Shikata, 1990), and mainly, PLMVd (Flores et al., 1992; Loreti et al., 1998; Osaki et al., 1999). Pear trees can be infected by all four viroids (Kyriakopoulou et al., 2001), but PBCVd is most frequently found. Almond trees can be infected only by HSVd (Cañizares et al., 1999) and apple tree by ASSVd (Hurtt et al., 1992; Yang et al., 1992; Kyriakopoulou et al., 2001). The symptoms caused by these viroids are not specific. PLMVd can induce early ageing of peach trees with irregularly shaped, flattened and colourless fruit (Desvignes, 1986; Flores et al., 1990; Llacer, 1998), and mosaic on leaves similar to those caused by viruses (Shamloul et al., 1995; Hadidi et al., 1997). Bark cankers caused by PBCVd on pear trees are similar to those caused by the fungus Venturia inaequalis (Desvignes et al., 1999). ASSVd causes a severe disease of apple, recognized by scarring around the calyx end of the fruit and cracking of the tissue (Koganezawa et al., 2003). Such symptoms are similar to those of frost damage or herbicides (J. Lemoine, INRA Angers, personnel communication). Furthermore, PLMVd and HSVd infection can be latent.

Detection methods for these viroids are needed as quick, sensitive, specific diagnostic procedures are a prerequisite for successful management of fruit-tree certification programmes. It is thus necessary to develop routine tests, compatible with analysis of many samples, for reliable and quick detection of these viroids. 
Biological indexing by grafting on woody indicators is cumbersome and time consuming. Such assays are inappropriate for screening a large number of samples, mostly because of greenhouse facilities and plant care requirements. As viroids do not code for any peptide or protein, detection based on serological techniques is not possible. Specific double-gel electrophoretic techniques (Schumacher et al., 1983; Flores et al., 1985) and nucleic acid hybridization (Owens and Diener, 1981) with radioactive or non-radioactive probes (Astruc et al., 1996) have been used for reliable detection of PLMVd, HSVd, ASSVd, and PBCVd in fruit trees, but such tests are not highly sensitive, so that low concentrations of viroids in woody material may remain undetected (Hadidi and Yang, 1990). Reverse transcription polymerase chain reaction (RT-PCR) tests have been developed for more sensitive detection. Single assays for detecting ASSVd (Hadidi and Yang, 1990), PLMVd (Loreti et al., 1999), PBCVd (Shamloul et al., 2002) and HSVd (Kofalvi et al., 1997) and multiplex assays of these four viroids (Ragozzino et al., 2004) have been performed. These, however, as they rely on labour-intensive preparation of nucleic acid extracts from the plant tissues to be tested, they need to be improved for routine detection of viroids in fruit trees.

Our objectives were to test for ASSVd, PBCVd, PLMVd and HSVd in trees growing in Tunisian orchards and to develop quick, simple individual RT-PCR tests using crude sap extracts.

\section{Materials and Methods \\ Source of orchard fruit trees}

Twenty-nine orchards were inspected: 19 in northern Tunisia (seven apple orchards, six pear orchards, four peach orchards, one almond-, peach-, and pear-tree orchard, and one almond-tree orchard) and 10 in the Sahel (three apple, pear, peach and almond orchards, two apple, pear and almond orchards, one apple, pear and peach orchard, one apple and pear orchard, one pear and peach orchard, one peach orchard, and one pear orchard). Orchard trees for testing (apple, pear, peach and almond) were mainly chosen on the basis of symptoms on leaves and bark potentially caused by ASSVd, PBCVd, PLMVd and HSVd. Three 1-year-old branches per tree were collected in May 2003, and stored at $4^{\circ} \mathrm{C}$. Bark and leaf tissues of these branches were analysed within 8 days. To minimize the effects of possible uneven viroid distribution, the samples were taken from different parts of the three branches collected from each tree. RNA and crude sap were extracted from these bark and leaf samples.

\section{Source of positive controls}

Twigs of ASSVd-infected indicator apple seedlings and PLMVd-infected GF 305 peach seedlings were provided by B. Pradier (Station de Quarantaine des Ligneux, Lempdes, France). These were viroid-positive as shown by chip budding of infected material on apple-seedlings (for ASSVd) or peach-seedlings (for
PLMVd) indicator plants grown under greenhouse conditions.

Leaves of a PLMVd-infected peach tree were provided by Dr Kyriakopoulou (Agricultural University of Athens, Votanikos, Athens, Greece). Total nucleic acid preparations from one ASSVd-infected apple tree, two PLMVd-infected peach trees, and one HSVd-infected cucumber plant were also provided by Dr R. Flores (Instituto de Biologia Molecular y cellular de Plantas, Valencia, Spain). In the absence of a characterized PBCVd isolate, the positive control for diagnosis of this viroid was a total RNA preparation of one sequenced amplification product obtained with PBCVd primers from preliminary tests on pear trees from Tunisia.

\section{RNA extraction from plant tissue}

RNA extracts were prepared as described by Grasseau et al. (1998), with some modifications. Leaf and bark tissues $(0.2 \mathrm{~g})$ were powdered in liquid nitrogen and homogenized with $1 \mathrm{ml}$ of $2 \mathrm{x}$ Sodium chloride-sodium citrate (SSC) buffer ( $3 \mathrm{M} \mathrm{NaCl}, 0.3 \mathrm{~m}$ sodium citrate, $\mathrm{pH} 7$ ) containing $1 \%$ sodium sulphite. After centrifugation at $16000 \times \boldsymbol{g}$ for $30 \mathrm{~min}$, the pellet was discarded and the supernatant mixed with $500 \mu \mathrm{l}$ of $10 \%$ non-ionic CF-11 cellulose (Whatman, Maidstone, UK). After shaking for $2 \mathrm{~h}$, the cellulose was collected by centrifugation and washed twice with $1 \mathrm{ml}$ of sodium chloride-TrisHcl EDTA (STE) buffer (10 mm Tris- $\mathrm{HCl}$ pH 8, $100 \mathrm{~mm}$ $\mathrm{NaCl}, 1 \mathrm{~mm}$ EDTA $\mathrm{pH} 8$ ) containing 35\% ethanol. RNA was released from the cellulose by washing twice with $300 \mu \mathrm{l}$ of STE buffer and precipitated with $700 \mu \mathrm{l}$ of isopropanol and $64 \mu \mathrm{l}$ of sodium acetate $(5 \mathrm{M}, \mathrm{pH}$ 5.2). Finally, the pellet was dried in a Speed-Vac (Savant, Farmingdale, NY, USA) and suspended in $30 \mu \mathrm{l}$ of diethylpyrocarbonate (DEPC)-treated water.

Concentration and extraction purities were estimated by measuring the absorbance of preparations at 260 and $280 \mathrm{~nm}$ with a spectrophotometer (Ultrospec II; LKB Biochrom, Cambridge, UK).

\section{Preparation of crude sap extract}

Crude sap extracts were prepared from the same plant material as used to prepare the RNA extracts. Leaves and bark tissue $(0.2 \mathrm{~g})$ were ground in a mortar with liquid nitrogen. Frozen pulverized tissue was transferred to $1.5 \mathrm{ml}$ of Eppendorf tube and mixed with $1 \mathrm{ml}$ of extraction buffer. Different extraction buffers were tested: (i) $136 \mathrm{~mm} \mathrm{NaCl}, 1 \mathrm{~mm} \mathrm{KH}_{2} \mathrm{PO}_{4}, 6 \mathrm{~mm}$ $\mathrm{Na}_{2} \mathrm{HPO}_{4}, 2 \mathrm{mM} \mathrm{KCl}, 15 \mathrm{mM} \mathrm{NaN}, 1 \% \mathrm{PVP}, 0.05 \%$ Tween (ELISA buffer); (ii) $136 \mathrm{mM} \mathrm{NaCl}, 16 \mathrm{~mm}$ $\mathrm{Na}_{2} \mathrm{HPO}_{4} \cdot 2 \mathrm{H}_{2} \mathrm{O}, 1 \mathrm{~mm} \mathrm{~K}_{2} \mathrm{HPO}_{4}, 2 \mathrm{~mm} \mathrm{KCl}, 3 \mathrm{~mm}$ $\mathrm{NaN}_{3}, 80 \mathrm{~mm} \mathrm{NaSO}, 0.05 \%$ Tween 20, pH 7.2-7.4 (B. Lockhart, University of Minnesota, personal communication); (iii) $200 \mathrm{~mm}$ Tris- $\mathrm{HCl}, \mathrm{pH} 8.5$ containing $1.5 \%$ sodium dodecylsulphate, $300 \mathrm{~mm}$ lithium chloride, $10 \mathrm{~mm}$ EDTA, 1\% sodium deoxycholate, 1\% NP40 (Spiegel et al., 1996); (iv) $2 \mathrm{X} \mathrm{SSC}$ buffer $(3 \mathrm{M} \mathrm{NaCl}$, $0.3 \mathrm{M}$ sodium citrate, $\mathrm{pH} 7$ ) supplemented with $1 \%$ Triton; (v) 2X SSC buffer supplemented with $1 \%$ Tween; (vi) 2X SSC containing 1\% sodium sulphite as 
Table 1

Viroid primers for reverse transcription polymerase chain reaction amplification

\begin{tabular}{|c|c|c|c|c|c|c|}
\hline Viroid & Primers & $\begin{array}{l}\text { Number } \\
\text { of bases }\end{array}$ & Sequence & Position & $\begin{array}{l}\text { Size of the } \\
\text { amplified } \\
\text { DNA (bp) }\end{array}$ & References \\
\hline \multirow[t]{2}{*}{ PLMVd } & cPLMVd & 25 & 5'AACTGCAGTGCTCCGAATAGGGCAC-3' & $91-115$ & \multirow[t]{2}{*}{337} & \multirow[t]{2}{*}{ Loreti et al. (1999) } \\
\hline & hPLMVd & 25 & 5'-CCCGATAGAAAGGCTAAGCACCTCG-3' & $116-140$ & & \\
\hline \multirow[t]{2}{*}{ PBCVd } & cPBCVd & 22 & 5'-CCTTCGTCGACGACGAGCCGAG-3' & $76-97$ & \multirow[t]{2}{*}{315} & \multirow[t]{2}{*}{ This study } \\
\hline & hPBCVd & 21 & 5'-GTCTAGAAGCCTGGGCGCTGG-3' & $98-118$ & & \\
\hline \multirow[t]{2}{*}{ ASSVd } & cASSVd & 20 & 5'-GCCTTCGTCGACGACGACAG-3' & $83-102$ & \multirow[t]{2}{*}{330} & \multirow[t]{2}{*}{ Di Serio et al. (2002) } \\
\hline & hASSVd & 21 & 5'-CGGTGAGAAAGGAGCTGCCAG-3' & $98-118$ & & \\
\hline \multirow[t]{2}{*}{ HSVd } & VP19 & 26 & 5'-GCCCCGGGGCTCCTTTCTCAGGTAAG-3' & $60-85$ & \multirow[t]{2}{*}{300} & \multirow[t]{2}{*}{ Astruc et al. (1996) } \\
\hline & VP20 & 25 & 5'-CCCGGGGCAACTCTTCTCAGAATCC-3' & $80-102$ & & \\
\hline
\end{tabular}

PLMVd, peach latent mosaic viroid; PBCVd, pear blister canker viroid; ASSVd, apple scar skin viroid; HSVd, hop stunt viroid.

an antioxidant. After centrifugation at $16000 \times \boldsymbol{g}$ for $30 \mathrm{~min}$ the supernatant was collected. Different dilutions $(10 \mathrm{x}, 50 \mathrm{x}, 100 \mathrm{x}, 500 \mathrm{x}, 1000 \mathrm{x})$ were prepared and stored at $-20^{\circ} \mathrm{C}$.

\section{Primer design}

We used primer pairs (Table 1) previously reported for RT-PCR amplification of ASSVd (Di Serio et al., 2002), PLMVd (Loreti et al., 1999) and HSVd (Astruc et al., 1996). For PBCVd, DNA amplification was carried out with the forward primer 5'-GTCTAGAAGCCTGGGCGCTGG-3' homologous to nucleotides 98-118 and the reverse primer 5'-CCTTCGTCGACGACGAGCCGAG-3' complementary to nucleotides 76-97 of PBCVd reference isolate P2098T (Hernandez et al., 1992) (Table 1). These primers were selected after analysis of the sequences of different PBCVd isolates by multiple alignment performed with CLUSTAL w software (Thompson et al., 1994). The primers were synthesized and purified (Eurogentec, Seraing, Belgium).

\section{RT-PCR assay}

RT-PCR was carried out on RNA preparations and crude sap extracts with the help of the One Tube RT-PCR Titan Kit (Roche Diagnostics, Penzberg, Germany). This allows RT and amplification to be performed sequentially in the same tube. Either 2- $\mu$ l aliquot containing $200 \mathrm{ng}$ nucleic acid extract or $2 \mu \mathrm{l}$ of diluted crude sap extract was mixed with $0.4 \mu \mathrm{mol}$ complementary primer. This mixture was heated for $5 \mathrm{~min}$ at $100^{\circ} \mathrm{C}$ and immediately chilled on ice. RT-PCR reaction mixtures (total volume $25 \mu \mathrm{l}$ ) contained $5 \mu \mathrm{l}$ of $5 \mathrm{x}$ RT-PCR buffer, $1.25 \mu \mathrm{l}$ of $100 \mathrm{~mm}$ dithiothreitol (DTT), $0.5 \mu \mathrm{l}$ of $10 \mu \mathrm{M}$ dATP, dCTP, dGTP and dTTP each, $0.4 \mu \mathrm{mol}$ of homologous primer, $0.5 \mu \mathrm{l}$ of enzyme mix (AMV reverse transcriptase and high-fidelity Taq polymerase), and DEPC-treated water to a volume of $22.5 \mu \mathrm{l}$. After addition of the denatured extract/complementary primer mixture, the RT-PCR reaction mixture was subjected to 30 amplification cycles [cycling parameters: $1 \mathrm{~h}$ at $50^{\circ} \mathrm{C}$ for cDNA synthesis, denaturing at $95^{\circ} \mathrm{C}$ for $3 \mathrm{~min}$ (first cycle) or $30 \mathrm{~s}$ (following cycles), primer annealing at $60^{\circ} \mathrm{C}$ for $45 \mathrm{~s}$, and extension at $72^{\circ} \mathrm{C}$ for $45 \mathrm{~s}$, followed by a final extension at $72^{\circ} \mathrm{C}$ for $7 \mathrm{~min}$.
Each RT-PCR run included a water control. RNA preparations from a PLMVd-free peach tree, a PBCVd- and HSVd-free pear tree and an ASSVd-free apple tree were included as healthy controls.

\section{Analysis of amplified RT-PCR products}

Aliquots $(10 \mu \mathrm{l})$ of each amplification product was electrophoresed in ethidium bromide-stained agarose gel $(2 \%)$ in $1 x$ TAE buffer $(40 \mathrm{~mm}$ Tris-acetate, $1 \mathrm{~mm}$ EDTA, pH 8.0).

\section{Cloning and sequencing of viroid cDNA}

RT-PCR products obtained from PLMVd-, PBCVdand HSVd-infected orchard fruit trees were directly cloned into the pCR ${ }^{\circledR} 2.1$ cloning vector with the help of the TA cloning Kit (Invitrogen, Groningen, The Netherlands), according to the manufacturer's instructions. The nucleotide sequences of cloned amplification products obtained from PLMVd, PBCVd and HSVd isolates were determined (GATC Biotech AG, Konstanz, Germany). Two clones per positive fruit tree were sequenced. Sequence analysis was performed with DNAMAN software (BioSoft, Lynnon, Canada).

\section{Results and Discussion \\ Development of a RT-PCR test for detecting PLMVd,} PBCVd, ASSVd and HSVd in fruit trees from RNA preparations

Development of the test from positive controls Specific amplification products of the expected size (c. $330 \mathrm{bp}$ for ASSVd, $315 \mathrm{bp}$ for PBCVd, $337 \mathrm{bp}$ for PLMVd and $300 \mathrm{bp}$ for HSVd) were obtained for all the positive controls. For each viroid, specificity of amplification was demonstrated by the lack of an amplification product when the primers were tested with extracts of trees infected by each of the three other viroids (data not shown). No band was obtained in negative controls (water and preparations from healthy trees). Figure 1 shows an example of results obtained with RNA preparations from positive controls for ASSVd, PBCVd, PLMVd and HSVd.

Application of the test on Tunisian fruit trees The test was then applied to RNA preparations from several 


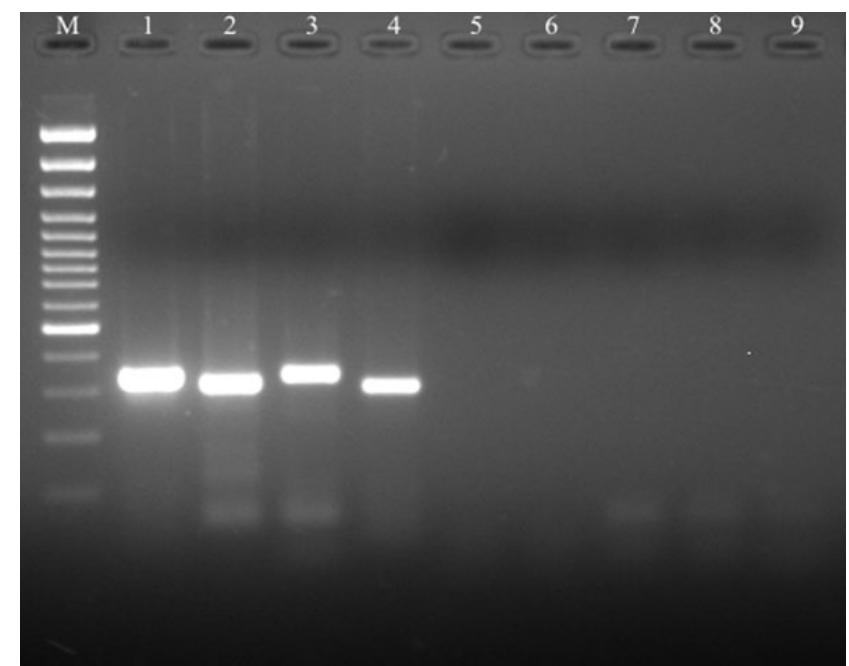

Fig. 1 Agarose gel electrophoretic analysis of reverse transcription polymerase chain reaction (RT-PCR) products amplified from total RNA preparations of viroid-infected tissues. RT-PCR product amplified from: apple scar skin viroid (ASSVd)-infected apple (lane 1), pear blister canker viroid (PBCVd)-infected pear (lane 2), peach latent mosaic viroid (PLMVd)-infected peach (lane 3) and hop stunt viroid (HSVd)-infected cucumber (lane 4). Negative controls included water (lane 5) and total RNA extracts from healthy apple, pear, peach and cucumber amplified with primers specific to ASSVd, PBCVd, PLMVd and HSVd respectively (lanes 6, 7,8 and 9, respectively). M: 100-bp DNA ladder plus (Gibco BRL, St. Leon-Rot, Germany)

Tunisian orchard fruit trees (results are summarized in Table 2).

PLMVd was detected in 12 of the 37 peach trees tested, results indicating that PLMVd is quite common in peach tree. Ten PLMVd-positive peach trees were in three orchards in the north and two in two different orchards in the Sahel. Twenty-five were negative for PLMVd. Two pear trees were positive for PLMVd. They occurred near each other and to one peach tree infected with PLMVd. This suggests that one of these trees may have served as a source of inoculum for the others through agronomic practices like pruning ( Hadidi et al., 1997) or via the aphid Myzus percicae (Desvignes et al., 1992). Alternatively, PLMVd may have originated in an unknown host and have been subsequently transmitted to the pear and stone fruit trees.
Of the 73 pear trees tested, PBCVd was detected in two orchards in the Sahel. This indicates that PBCVd is not widespread in Tunisia and suggests that the two pear trees may have originated from the same presumably infected mother tree.

HSVd was found in five proximal pear trees in one orchard in the Sahel and two other adjacent pears trees in another orchard, also in the Sahel. Among the 12 almond trees tested, two were positive for HSVd; one tree was in the north and the other was proximal to the only HSVd-infected peach tree found in an orchard in the Sahel. It is most likely that HSVd was transmitted between peach and almond trees and between pear trees mechanically or through grafting (Desvignes et al., 1992) or that the source of infection was the mother tree. None of the 62 tested pome trees was positive for ASSVd.

Mixed infections were observed only in pear trees in the Sahel: one tree was infected with a complex of PBCVd and HSVd and another with PLMVd and HSVd. These trees were found in the same orchard containing PBCVd-infected pear trees, HSVd-infected pear trees, and PLMVd-infected peach trees. It is very likely that contaminated knives were responsible for these mixed infections. To our knowledge, this is the first report of mixed infections in cultivated pear trees.

The symptoms affecting the leaves bark, and fruits of the fruit trees tested were not consistently associated with the presence of viroids (results not shown). Furthermore, the trees from which the samples were taken were growing under uncontrolled conditions, so they might have been subject to other types of biotic or abiotic stress.

PLMVd, PBCVd and HSVd, amplification products obtained from different fruit trees were cloned for sequencing. Two PBCVd isolates from pear trees shared high sequence identity $(99 \%)$ with variants of the isolates P1914T (GenBank accession nos Y18035 and Y18036), P47A (GenBank accession nos Y18037Y18044) and P2098T (GenBank accession no. D12823). For PLMVd, three isolates from peach trees and one isolate from a pear tree were sequenced. The four isolates shared $85-98 \%$ homology with the Italian PC-C32 isolate of PLMVd from peach (GenBank

Table 2

Number of trees infected with PLMVd, HSVd, PBCVd or ASSVd

\begin{tabular}{|c|c|c|c|c|c|c|c|}
\hline \multirow[b]{2}{*}{$\begin{array}{l}\text { Nature } \\
\text { of tree }\end{array}$} & \multirow[b]{2}{*}{$\begin{array}{l}\text { Total number } \\
\text { of tested trees }\end{array}$} & \multirow[b]{2}{*}{ Region } & \multirow{2}{*}{$\begin{array}{l}\text { Number of } \\
\text { tested tree in } \\
\text { each region }\end{array}$} & \multicolumn{4}{|c|}{ Number of trees infected with } \\
\hline & & & & PLMVd & HSVd & PBCVd & ASSVd \\
\hline \multirow[t]{2}{*}{ Peach trees } & 37 & North & 22 & 10 & 0 & 0 & NT \\
\hline & & Sahel & 15 & 2 & 1 & 0 & NT \\
\hline \multirow[t]{2}{*}{ Pear trees } & 73 & North & 31 & 0 & 0 & 0 & 0 \\
\hline & & Sahel & 42 & 2 & 7 & 2 & 0 \\
\hline \multirow[t]{2}{*}{ Almond trees } & 12 & North & 3 & NT & 1 & NT & NT \\
\hline & & Sahel & 9 & NT & 1 & NT & NT \\
\hline \multirow[t]{2}{*}{ Pome trees } & 62 & North & 48 & NT & NT & NT & 0 \\
\hline & & Sahel & 14 & NT & NT & NT & 0 \\
\hline
\end{tabular}

NT, not tested; PLMVd, peach latent mosaic viroid; PBCVd, pear blister canker viroid; ASSVd, apple scar skin viroid; HSVd, hop stunt viroid. 
accession no. AJ550905). Two HSVd isolates, one from almond and one from peach, were sequenced. They shared $99-100 \%$ identity with HSVd from dapple plum fruit (GenBank accession no. AY460202). For a same isolate, the two tested clones showed sequence homogeneity of $99 \%$ for HSVd and 97$100 \%$ for PLMVd. No variability was found between the two clones of a same PBCVd isolate. These sequencing results confirmed the specificity of the RT-PCR assays.

\section{Simplification of the RT-PCR test by using crude sap extract with adequate extraction buffer}

The preparation of RNA extracts is not suitable for routine use in diagnostic laboratories. RT-PCR was thus simplified by using directly diluted crude plant extracts. The assay was conducted on crude sap extracts of leaves or bark tissue from one ASSVdinfected apple tree (from France), two PBCVd-infected pear trees, eight PLMVd-infected peach trees, one HSVd-infected almond tree, two HSVd-infected peach trees, and one HSVd-infected pear tree from Tunisia. Six different extraction buffers were tested. For each viroid, the signal intensity was highest when SSC buffer containing $1 \%$ sodium sulphite was used as extraction buffer. For all four viroids, the signal intensity was higher for sap diluted 50x and 100x than for the other dilutions used $(10 x, 500 x$ and 1000x). Whatever the viroid, no signal was observed at a 10 -fold dilution. Figures 2 and 3 illustrate, respectively, the results obtained for PLMVd-infected peach with the different buffers tested and for PBCVd-infected pear with the selected buffer SSC plus sodium sulphite. At 50x or higher dilution the inhibitory effects of crude plant extracts on the amplification reaction, probably due to plant polysaccharides or phenolic compounds, were avoided. With the selected buffer, the test using crude plant extracts from leaves or bark tissue consistently yielded results comparable to those obtained with purified RNA preparations (Fig. 4).

This rapid and simple extraction method avoids the use of harmful organic solvents. As it is performed in a single closed tube, the risk of contamination between the reverse transcription and amplification steps is reduced. The test can be performed on 30 samples in $7 \mathrm{~h}$. It is thus a viroid detection and identification method suitable for routine diagnosis of many samples.

We report for the first time the presence of PLMVd, PBCVd and HSVd in fruit trees in Tunisia. Our RT-PCR tests, which are directly applicable to crude plant extracts, offer quick, easy detection of viroids in fruit-tree leaves or bark. We thus propose the use of this test to screen fruit trees for viroids in certification programmes aiming to prevent the occurrence and spread of fruit-tree viroids in Tunisia. This test could be used to: (i) study the distribution of PLMVd (the viroid most common in Tunisian orchards); (ii) detect field reservoirs of this viroid; (3) confirm or rule out transmission of PLMVd by aphids (which to date has

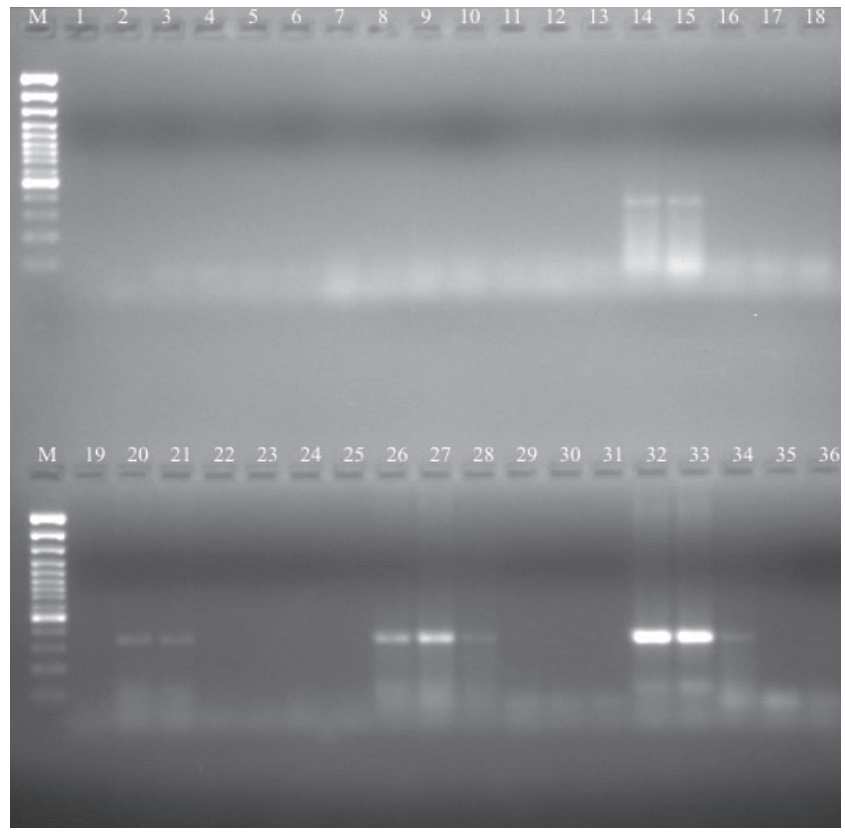

Fig. 2 Comparative analysis of reverse transcription polymerase chain reaction (RT-PCR) amplification products obtained from diluted crude sap extracts of peach latent mosaic viroid-infected peach prepared with six different extraction buffers. Lanes 1-5: ELISA buffer, dilutions $1 / 10,1 / 50,1 / 100,1 / 500$ and $1 / 1000$ respectively; lanes 7-11: Lockhart buffer $1 / 10,1 / 50,1 / 100,1 / 500$ and $1 / 1000$ respectively; lanes 13-17: Spiegel buffer $1 / 10,1 / 50,1 / 100,1 / 500$ and $1 / 1000$ respectively; lanes 19-23: SSC buffer complemented with Triton; 1/ $10,1 / 50,1 / 100,1 / 500$ and $1 / 1000$ respectively; lanes 25-29: SSC buffer complemented with Tween, $1 / 10,1 / 50,1 / 100,1 / 500$ and $1 / 1000$ respectively; lanes 31-35: SSC buffer complemented with sodium sulphite, $1 / 10,1 / 50,1 / 100,1 / 500$ and $1 / 1000$ respectively; lane $6,12,18$, 24, 30 and 36: RT-PCR product amplified from crude sap extract of healthy peach prepared, respectively, with the ELISA, Lockhart, Spiegel, SSC complemented with Triton, Tween or sodium sulphite buffers (dilutions 1/100). M: 100-bp DNA ladder plus (Gibco BRL)

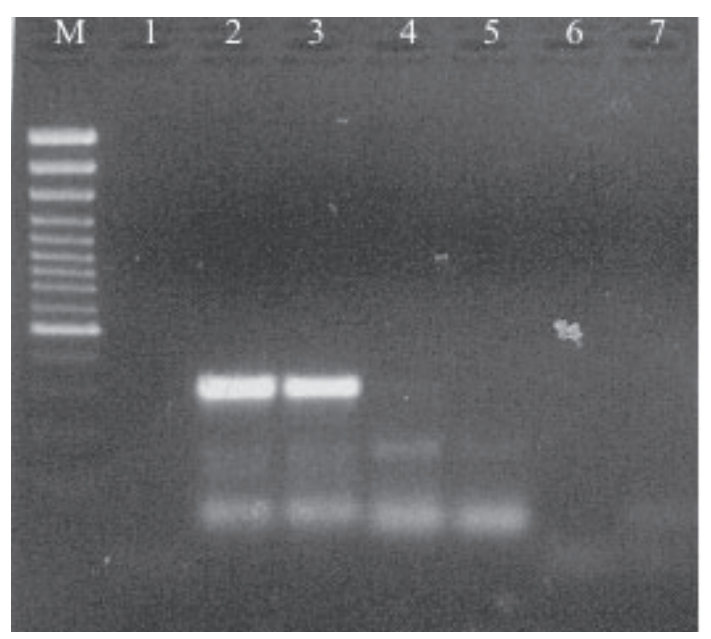

Fig. 3 Agarose gel electrophoretic analysis of reverse transcription polymerase chain reaction products amplified from crude sap extract of pear blister canker viroid-infected pear prepared with the SSC buffer complemented with sodium sulphite and diluted 1/10 (lane 1), $1 / 50$ (lane 2), 1/100 (lane 3), 1/500 (lane 4) and 1/1000 (lane 5). Negative controls included water (lane 6) and crude sap extract from healthy pear (lane 7). M: 100-bp DNA ladder plus (Gibco BRL) 


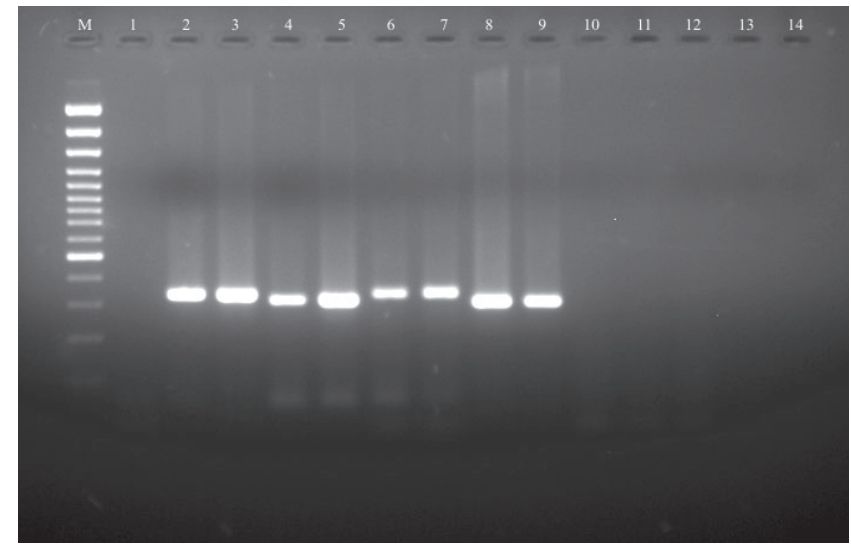

Fig. 4 Comparative analysis of reverse transcription polymerase chain reaction amplification products obtained from diluted crude sap extracts prepared with SSC buffer complemented with sodium sulphite and total RNA extracts from viroid-infected tissues. Lane 1: crude sap extract of apple scar skin viroid (ASSVd)-infected apple, dilution 1/10; lane 2: crude sap extract of ASSVd-infected apple, dilution 1/100; lane 3: total RNA extract of ASSVd-infected apple; lane 4: crude sap extract of pear blister canker viroid (PBCVd)-infected pear, dilution 1/100; lane 5: total RNA extract of PBCVd-infected pear; lane 6: crude sap extract of peach latent mosaic viroid (PLMVd)-infected peach, dilution 1/100; lane 7: total RNA extract of PLMVd-infected peach; lane 8: crude sap extract of hop stunt viroid (HSVd)-infected almond, dilution 1/100; lane 10 total RNA extract of HSVd-infected almond. Negative controls included water and crude extracts from healthy apple, pear, peach and almond (lanes 10,11, 12, 13 and 14 respectively). M: 100-bp DNA ladder plus (Gibco BRL)

only been demonstrated experimentally; Desvignes et al., 1992) and (iv) identify possible new plant hosts for this viroid.

\section{Acknowledgements}

This work was supported by the 'Commissariat Général aux Relations Internationales' (CGRI) and by the 'Ministère tunisien de l'Enseignement supérieur de la Recherche scientifique et de la Technologie'. The authors are grateful to Dr R. Flores, Dr P. E. Kyriakopoulou and Dr B. Pradier for kindly providing infected material.

\section{References}

Astruc N, Marcos JF, Macquaire G, Candresse T, Pallas V. (1996) Studies on the diagnosis of hop stunt viroid in fruit trees: identification of new hosts and application of a nucleic acid extraction procedure based on non-organic solvents. Eur J Plant Pathol 102:837-846.

Cañizares MC, Marcos JF, Pallas V. (1999) Molecular characterization of an almond isolate of hop stunt viroid (HSVd) and conditions for eliminating spurious hybridization in its diagnosis in almond samples. Eur J Plant Pathol 105:553-558.

Desvignes JC. (1986) Peach latent mosaic and its relation to peach mosaic and peach yellow virus diseases. Acta Hortic 193:51-57.

Desvignes JC, Flores R, Llacer G. (1992) Les maladies de dégénérescence des arbres fruitiers provoquées par des viroïdes. Phytoma 444:70-74.

Desvignes JC, Cornaggia D, Grasseau N. (1999) Pear blister canker viroid: host range and improved bioassay with two new pear indicators, Fieud 37 and Fieud 110. Plant Dis 83:419-422.

Di Serio F, Malfitano M, Alioto D, Ragozzino A, Flores R. (2002) Apple dimple fruit viroid: sequence variability and its specific detection by multiplex fluorescent RT-PCR in the presence of apple scar skin viroid. Plant Pathol 84:27-34.

Diener TO. (1971) Potato spindle tuber virus: a plant virus with properties of a free nucleic acid. III. Subcellular location of PSTV-
RNA and the question of whether virions exist in extracts or in situ. Virology 43:75-89.

Flores R, Duran-Vila N, Pallas V, Semancik J. (1985) Detection of viroid and viroid-like RNAs from grapevine. J Gen Virol 66:20952102.

Flores R, Hernandez C, Desvignes JC, Llacer G. (1990) Some properties of the viroid inducing peach latent mosaic disease. Res Virol 141:109-118.

Flores R, Hernandez C, Avinent L, Llacer G, Arregui JM, Hermoso A, Juarez J, Navarro L, Desvignes JC. (1992) Studies of the detection, transmission and distribution of peach latent mosaic viroid (PLMVd) in peach trees. Acta Hortic 309:325-330.

Flores R, Randles JW, Bar-Joseph M, Diener TO. (1998) A proposed scheme for viroid classification and nomenclature. Arch Virol 143:623-629.

Grasseau N, Macquaire G, Desvignes JC. (1998) Détection des viroïdes des arbres fruitiers par hybridation moléculaire. Infos-CTIFL 143:26-29.

Hadidi A, Yang X. (1990) Detection of pome fruit viroids by enzymatic cDAN amplification. J Virol Methods 30:261-270.

Hadidi A, Giunchedi L, Shamloul AM, Poggi-Pollini C, Amer MA (1997) Occurrence of peach latent mosaic viroid in stone fruits and its transmission with contaminated blades. Plant Dis 81:154-158.

Hernandez C, Elena SF, Moya A, Flores R. (1992) Pear blister canker viroid is a member of the apple scar skin subgroup (apscaviroids) and also has sequence homology with viroids from other subgroups. J Gen Virol 73:2503-2507.

Hurtt SS, Podleckis EV, Ibrahim LM, Hadidi A. (1992) Early detection of apple scar skin group viroids from imported pear germplasm. Acta Hortic 309:311-319.

Kofalvi SA, Marcos JF, Cañizares MC, Pallas V, Candresse T. (1997) Hop stunt viroid (HSVd) sequence variants from Prunus species: evidence for recombination between HSVd isolates. $J$ Gen Virol 78:3177-3186.

Koganezawa H, Yang X, Zhu SF, Hashimoto J, Hadidi A. Apple scar skin viroid in apple. In: Hadidi A, Flores R, Randles JW, Semancik JS (eds), Viroids, Collingwood, Australia, CSIRO, 2003, pp. 137-141.

Kyriakopoulou PE, Giunchedi L, Hadidi A. (2001) Peach latent mosaic and pome fruit viroids in naturally infected cultivated pear (Pyrus communis) and wild pear $P$. amygdaliformis: implications on possible origin of these viroids in the Mediterranean region. J Plant Pathol 83:51-62.

Llacer G. (1998) General aspects of peach latent mosaic disease. Acta Hortic 472:561-564

Loreti S, Faggioli F, Barrale R, Barba M. (1998) Occurrence of viroids in temperate fruit trees in Italy. Acta Hortic 472:555-559.

Loreti S, Faggioli F, Cardoni M, Mordenti G, Babini AR, Poggi Pollini C, Barba M. (1999) Comparison of different diagnostic methods for detection of peach latent mosaic viroid. Bull OEPP 29:433-438.

Osaki H, Yamaguchi Y, Sato Y, Tomita Y, Kawai Y, Miyamoto Y, Ohtsu Y. (1999) Peach latent mosaic viroid isolated from stone fruits Japan. Ann Phytopathol Soc Jpn 65:3-8.

Owens R, Diener T. (1981) Sensitive and rapid diagnosis of potato spindle tuber viroid disease by nucleic acid spot hybridization. Science 213:670-672.

Ragozzino E, Faggioli F, Barba M. (2004) Development of a one tube-one step RT-PCR protocol for the detection of seven viroids in four genera: Apscaviroid, Hostuviroid, Pelamoviroid and Pospiviroid. J Virol Methods 121:25-29.

Randles JW. Economic impact of viroid diseases. In: Hadidi A, Flores R, Randles JW, Semancik JS (eds), Viroids, Collingwood, Australia, CSIRO, 2003, pp. 3-11.

Sano T, Hataya T, Terai Y, Shikata E. (1989) Hop stunt viroid strains from dapple fruit disease of plum and peach in Japan. J Gen Virol 70:1311-1319.

Schumacher J, Randles J, Riesner D. (1983) A two-dimensional electrophoresis technique for the detection of circular viroids and virusoids. Ann Biochem 135:288-295.

Shamloul AM, Minafra A, Hadidi A, Giunchedi L, Waterworth HE, Allam EK. (1995) Peach latent mosaic viroid: nucleotide sequence 
of an Italian isolate, sensitive detection using RT-PCR and geographic distribution. Acta Hortic 386:522-530.

Shamloul AM, Faggioli F, Keith JM, Hadidi A. (2002) A novel multiplex RT-PCR probe capture hybridization (RT-PCR-ELISA) for simultaneous detection of six viroids in four genera: Apscaviroid, Hostuviroid, Pelamoviroid, and Pospiviroid. J Virol Methods 105:115-121.

Shikata E. (1990) New viroids from Japan. Semin Virol 1:107-115.

Spiegel S, Scott SW, Bowman-Vance V, Tam Y. (1996) Improved detection of prunus necrotic ringspot virus by the polymerase chain reaction. Eur J Plant Pathol 102:681-685.
Thompson JD, Higgins DG, Gibson TJ. (1994) CLUSTAL W: improving the sensitivity of progressive multiple sequence alignment through sequence weighting position-specific gap penalties and weight matrix choice. Nucleic Acids Res 22:4673-4680.

Yang X, Hadidi A, Hammond RW. (1992) Nucleotide sequence of apple scar skin viroid reverse-transcribed in host extracts and amplified by the polymerase chain reaction. Acta Hortic 309:305309. 